\title{
The Four Fixation Points of the Axis: Technique and Case Report
}

\author{
KRIS SIEMIONOW, MD, ${ }^{1}$ PIOTR JANUSZ, MD,${ }^{1,2}$ STEVEN MARDJETKO, MD ${ }^{3}$ \\ ${ }^{I}$ Department of Orthopaedics, University of Illinois, Chicago, Illinois ${ }^{2}$ Department of Spine Disorders and Pediatric Orthopedics, University of Medical Sciences, \\ Poznan, Poland ${ }^{3}$ Illinois Bone and Joint Institute, Chicago, Illinois
}

\begin{abstract}
Background: Instrumentation of the axis can be accomplished through a variety of techniques including transarticular screw fixation, pars and pedicle screw fixation, translaminar screw fixation, and posterior wiring. We report on the evolution of the axial 4-screw technique.

Methods: Retrospective case review. After exposure of posterior spinal elements, the medial and superior walls of the $\mathrm{C} 2$ pedicle were identified from within the spinal canal. A high-speed drill was then advanced under lateral fluoroscopy, which guided craniocaudal angulation. Medial angulation was based on anatomic landmarks and preoperative imaging. This was followed by placement of translaminar screws according to the technique described by Wright. When extending the construct into the subaxial spine or the occiput, lateral connectors are placed in translaminar screws, which are usually more offset. The rod is directly connected to the pedicle screws, which are usually more in alignment with the subaxial/occipital instrumentation.

Results: Two male patients ages 56 and 58 underwent posterior instrumentation of the axis employing a combination of pedicle and laminar polyaxial screws. Indications included multilevel spinal cord compression and deformity in a patient with Down syndrome and cervical meningioma, respectively. Follow-up was 1 year and 5 years, respectively. Medical complications $(\mathrm{N}=2$ ) occurred in the patient with Down syndrome resulting in prolonged intubation with tracheostomy placement. Reduction was maintained in both patients at last follow-up. There were no neurologic, vascular, or instrumentation related complications.

Conclusions: The axis serves as a versatile anchor point and offers 4 potential points of fixation. Lateral connectors play a crucial role and allow for incorporation of the $\mathrm{C} 2$ screws with the rest of the construct. Local anatomy will dictate the necessity and ability to place instrumentation and detailed preoperative planning is of paramount importance.
\end{abstract}

Cervical Spine

Keywords: axis, pedicle screws, translaminar screws, posterior cervical fixation, C2 fixation, C2 screws

\section{INTRODUCTION}

Instrumentation of the axis can be accomplished through a variety of techniques, including transarticular screw fixation, pars and pedicle screw fixation, translaminar screw fixation, hook fixation, and posterior wiring. ${ }^{1-5}$ Developments in instrumentation, image guidance/navigation, and surgical techniques have led to the placement $\mathrm{C} 2$ pars, pedicle, and laminar screws. ${ }^{3,5-7}$ In order to maximize the potential of the axis as a fixation point, we report on the evolution of our 4-screw technique consisting of $2 \mathrm{C} 2$ translaminar screws and $2 \mathrm{C} 2$ pedicle screws.

\section{MATERIALS AND METHODS}

This is a retrospective review of patients who had instrumentation at $\mathrm{C} 2$. All patients underwent pre- and postoperative cervical x-rays, magnetic resonance imaging, and thin-cut computed tomography (CT) scans with sagittal and coronal reconstructions. All patients had a minimum of 1 year of follow-up.

\section{Surgical Technique}

After application of Garden-Wells tongs, the patient is positioned prone on a radiolucent Jackson table. Lateral $\mathrm{x}$-ray is taken to assess cervical spine alignment. After exposure, the polyaxial pedicle screws are placed first. ${ }^{5}$ This ensures that there will be no interference from the distal tips of the laminar screws. The medial and superior walls of the C2 pedicle are first identified from within the canal with a \#1 Pennfield. A high-speed drill is then advanced under lateral fluoroscopy, which guides craniocaudal angulation. Medial angulation is based on 


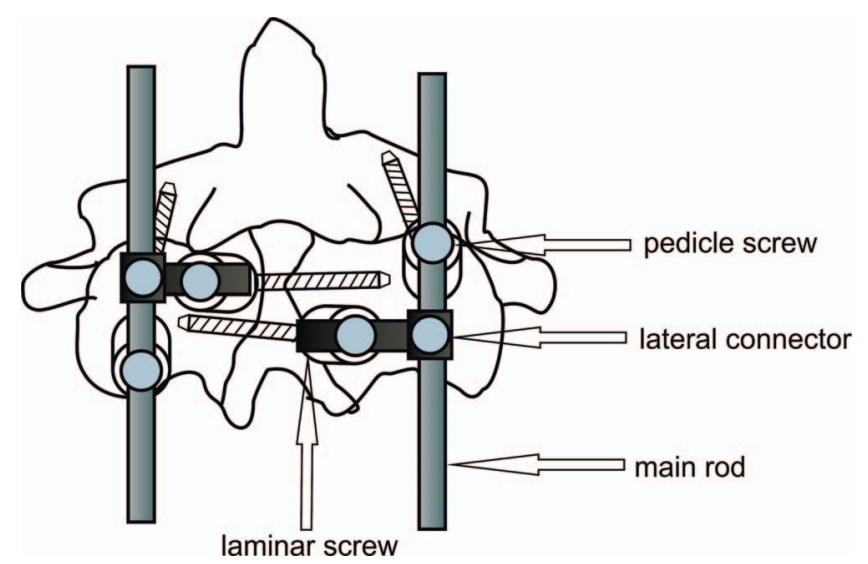

Figure 1. Schematic diagram describing position of the screws with offset connectors.

anatomic landmarks and preoperative imaging. This is followed by placement of polyaxial translaminar screws according to the technique described by Wright. ${ }^{8}$ It is recommended to leave all of the screw heads slightly proud to allow for maximal polyaxial rotation. When extending the construct into the subaxial spine, we use lateral connectors in the translaminar screws, which are usually more offset, and directly connect the rod to the pedicle screws, which are usually more in alignment with the subaxial instrumentation. ${ }^{5}$ Finally, the construct obtained at the $\mathrm{C} 2$ level consisted of a main rod passing through a $\mathrm{C} 2$ pedicle screw head with additional fixation with a translaminar screw linked by a lateral connector connected perpendicularly to the main rod (in similar manner as typical transversal connectors) (Figure 1).

\section{Case Report}

\section{Case 1}

The patient was a 56-year-old male with Down syndrome, cervical spinal stenosis, and spinal cord compression and myelopathy. In addition to subluxation of $\mathrm{C} 5$ on $\mathrm{C} 6$, the patient had cervical deformity with multiple dysplastic vertebrae (Figure 2). Preoperative imaging demonstrated good $\mathrm{C} 2$ pedicle, pars, and lamina (Figure 3). Due to limited bony anchor points in the subaxial cervical spine (lateral mass hypoplasia) and a planned large suboccipital decompression limiting anchor point options in the skull, we decided to maximize the amount of bony anchor points in the axis with 4point fixation at the $\mathrm{C} 2$ level. He was placed in preoperative halo traction, which was followed by posterior cervical decompression at $\mathrm{C} 5-\mathrm{C} 7$ and instrumented (DePuy/Synthes, Raynham, Massachusetts) fusion from $\mathrm{C} 2$ to T2. Two pedicle and 2 translaminar screws were placed in the axis (Figure 4). This was connected with the rest of the construct via lateral connectors (Figure 5). The patient tolerated the procedure well. Postoperative CT scan demonstrated good hardware positioning (Figure

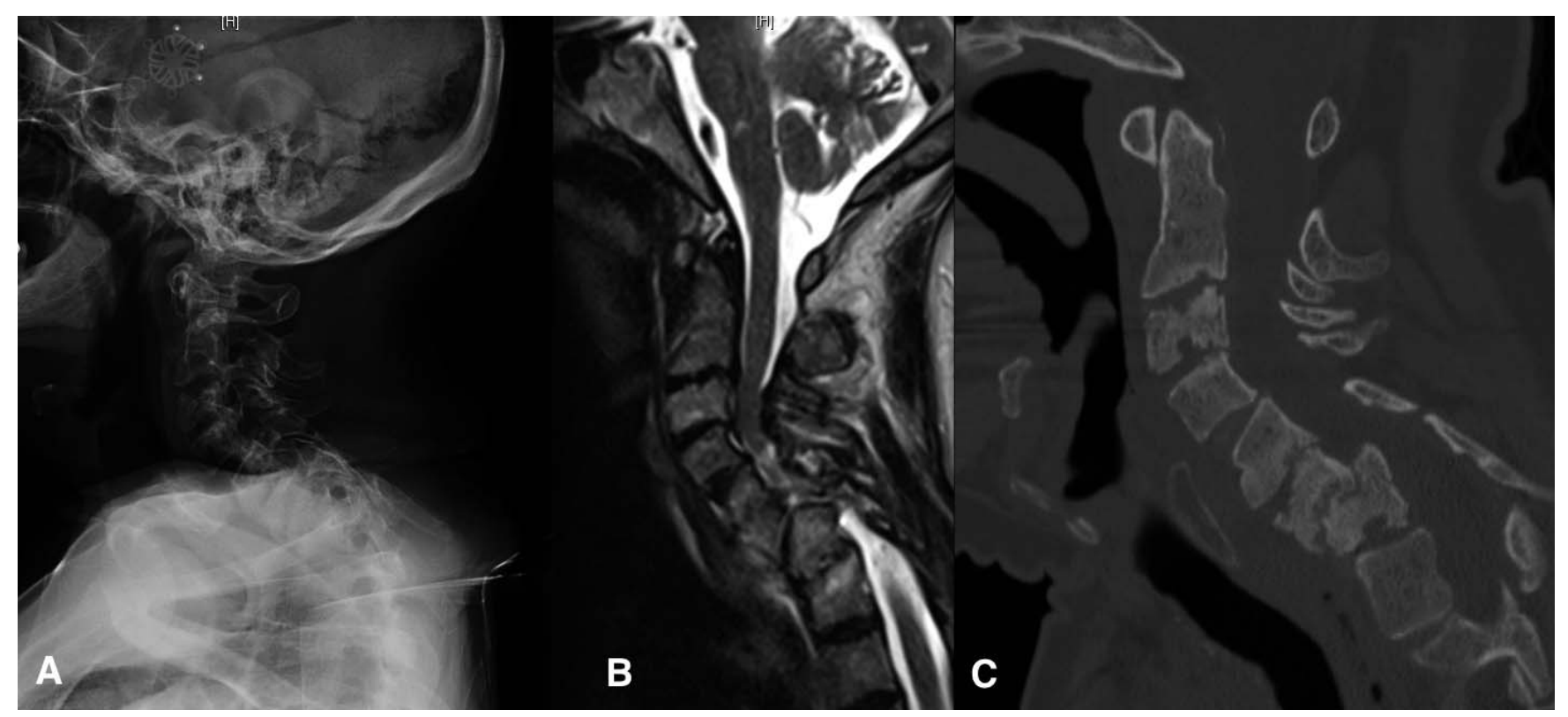

Figure 2. (A) Lateral x-ray of the cervical spine of a 56-year-old male with Down syndrome and progressive myelopathy. (B) Sagittal magnetic resonance imaging demonstrates severe multilevel spinal cord compression with myelomalacia. (C) Sagittal computed tomography scan demonstrates C6-C7 spondylolishtesis with advanced degenerative changes and endplate erosions at C2-C3, C3-C4, C5-C6, and C6-C7. 


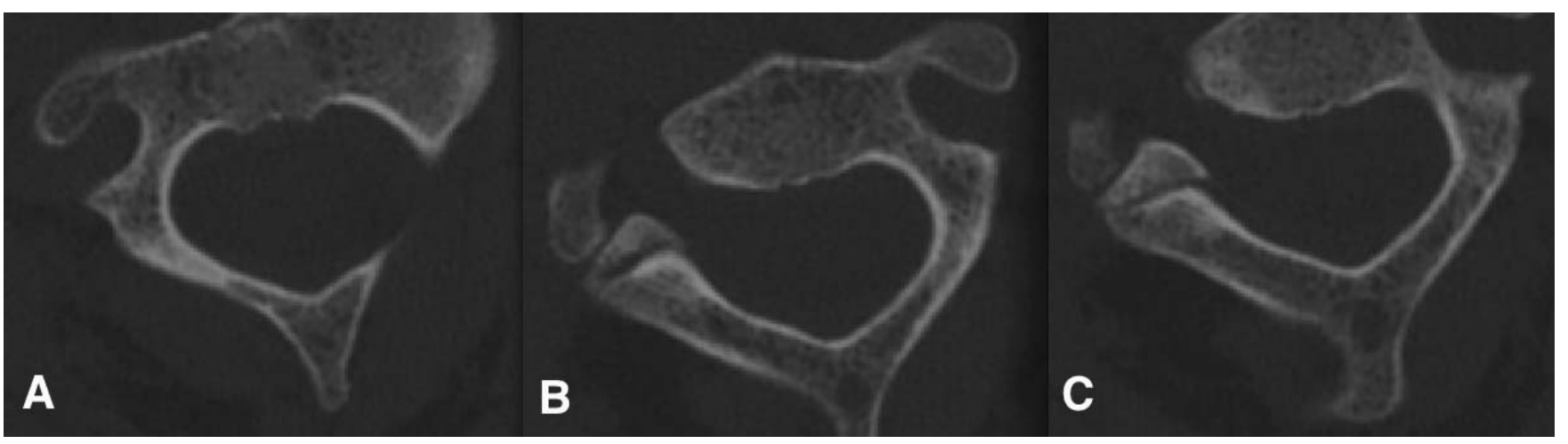

Figure 3. Axial computed tomography scan throughout the $\mathrm{C} 2$ vertebral body at the level of the pedicles demonstrating the right (A) pedicle, left (B) pedicle, and the lamina. Preoperative planning is critical to both implant and technique selection.

6). There was no loss of reduction at 1-year followup (Figure 7).

\section{Case 2}

The patient was a 60 -year-old male who presented with neck pain and restricted cervical range of motion. Advanced imaging demonstrated a lesion in the $\mathrm{C} 2$ vertebral body with advanced bony destruction and fracture. Biopsy reveled meningioma. Due to changes in bone structure influenced by lesion and poor intraoperative purchase, we decided to augment the $\mathrm{C} 2$ pedicle screws with translaminar fixation. The patient underwent an instrumented occiput to $\mathrm{C} 3$ posterior spinal fusion via a unilateral construct consisting of a $\mathrm{C} 2$ pedicle and a translaminar screw. There was destruction of the left $\mathrm{C} 2$

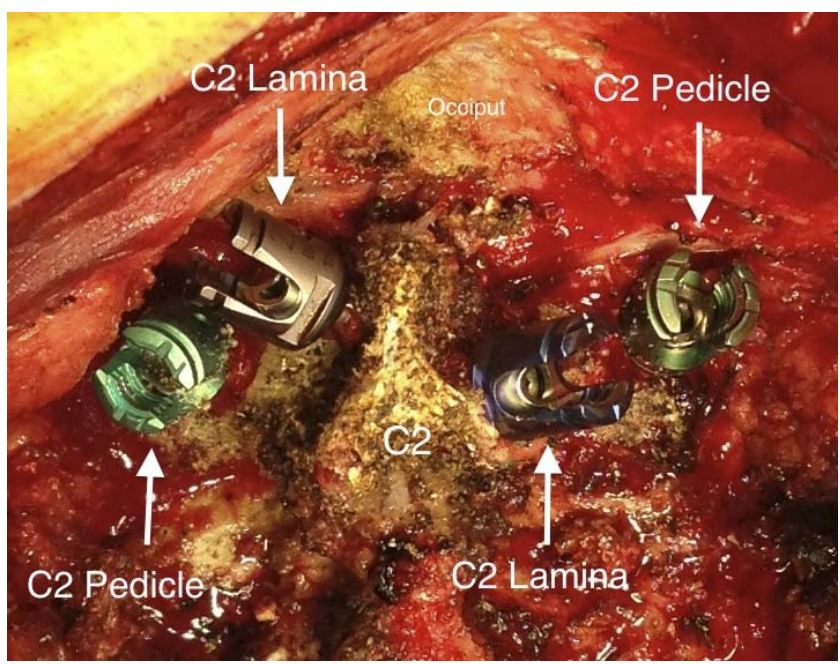

Figure 4. Intraoperative photograph demonstrating placement of polyaxial pedicle screws into the pedicle and lamina of the axis. Preoperative planning is critical to ensure that all 4 screws can be safely placed into the pars/pedicle and lamina of the axis. pedicle; therefore, no pedicle screw was placed on that side. At 5-year follow-up, he had a solid posterior arthrodesis with no evidence of hardware failure (Figure 8).

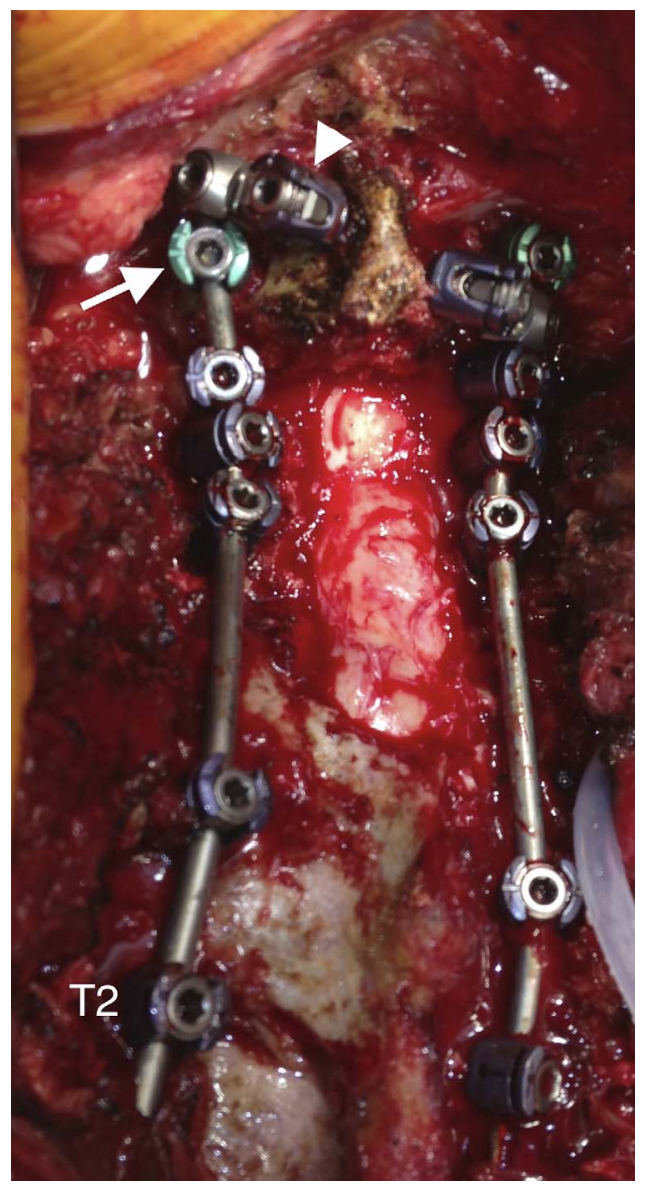

Figure 5. Intraoperative photograph demonstrating the use of lateral connectors to connect the rod to the translaminar screw. The left translaminar screw (arrowhead) is attached to the main rod via a cross connector that is anchored to the rod cephalad to the C2 pedicle screw (arrow). The pedicle screws are usually more in line with the rest of the construct and can be directly connected to the rod. Central laminectomy from C5 to C7 is visualized. 


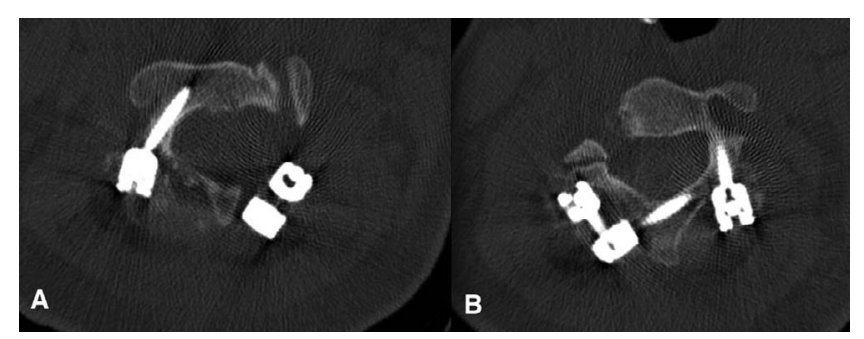

Figure 6. Postoperative axial computed tomography scan of the $\mathrm{C} 2$ vertebrae demonstrating a right-sided $\mathrm{C} 2$ pedicle screw $(\mathrm{A})$ and a left-sided laminar screw (B).

\section{DISCUSSION}

Instrumentation of $\mathrm{C} 2$ can be accomplished via multiple possible constructs. ${ }^{5}$ Both the $\mathrm{C} 2$ lamina and the pedicle have been shown to have sufficient dimensions to accept bone anchors. ${ }^{9,10}$ This case report demonstrates the feasibility of safely placing 4 polyaxial screws into the axis. It is important to note that constructs with unilateral $\mathrm{C} 2$ pedicle and lamina fixation are an option in cases precluding bilateral fixation. We feel that this technique may reduce the chance of construct failure, especially in the presence of osteoporotic bone and poor lateral mass screw purchase.

The construct requires the use of lateral connectors. Although there is no rule regarding which $\mathrm{C} 2$ screw (pedicle vs lamina) will be best suited for a lateral connector, we usually find that the pedicle screws are in line with the distal lateral mass screws, while the laminar screws are more offset and require a cross connector. We prefer to leave the screws 2 to $4 \mathrm{~mm}$ proud to allow for screw head rotation as well as to close the distance between the tulip and the rod. The main issue is to place pedicular screws first to avoid interference from the distal tips of the laminar screws.

Although specific biomechanical evaluation of 4point $\mathrm{C} 2$ fixation has not been described, reports concerning stabilization of the operated spine segment show superiority of pedicular fixation over translaminar screw fixation, especially in lateral bending. ${ }^{11}$ The evaluation of the pullout strength demonstrated that pedicle screws provide the strongest fixation for both initial and salvage applications; however, in salvage applications, translaminar screws provide stronger fixation than pars screws. ${ }^{12}$ The main theoretical advantage of the 4-point fixation technique is the fact that adding translaminar screws to the pedicular fixation should result in an increase in both the strength and the endurance of the construct. Four distinct points of

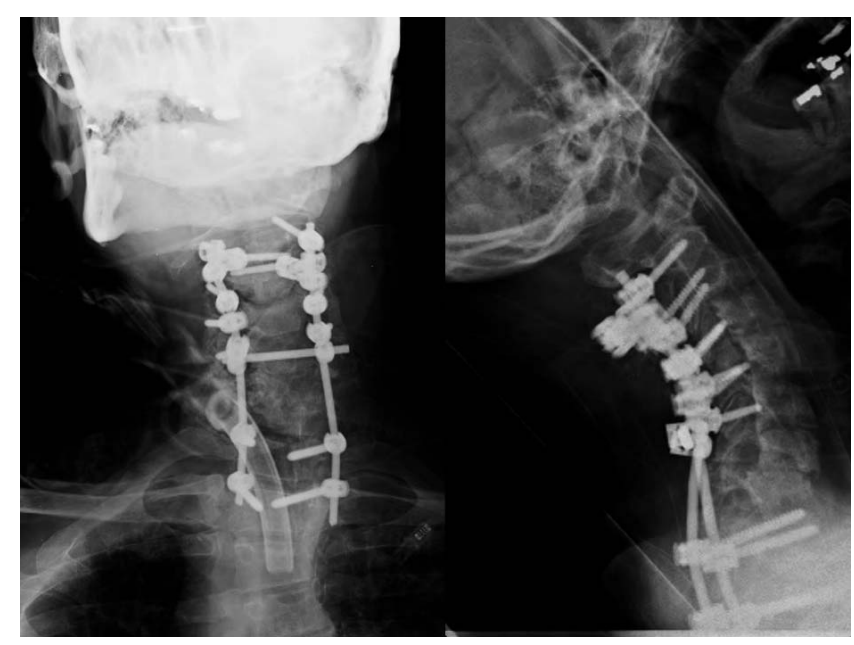

Figure 7. Postoperative antero-posterior and lateral x-rays taken 6 months postoperatively demonstrate maintenance of cervical lordosis.

fixation at the same level, with screws placed at different angles and connected to the same rod, should provide high durability against pullout force.

The main disadvantage of placing 4 points of fixation at $\mathrm{C} 2$ is that it uses translaminar stabilization in the index surgery, whereas it is often used as a salvage fixation technique in case of revision surgery. Although we believe that 4 bony anchors at $\mathrm{C} 2$ may reduce instrument failures, in cases where revision surgery is necessary, other techniques, such as wiring, hook placement, or transarticular screws, are still possible. ${ }^{5}$

The implantation technique is based on welldescribed standardized instrumentation methods and does not introduce any new complications; however, increasing the amount of bony work at any spinal level increases the risk proportionately, and complications typical for each of the techniques may occur. Possible technical problems with screw arrangement and connection of the implants may be avoided with careful preoperative planning.

The 4-point $\mathrm{C} 2$ fixation method is not a routine procedure and should be considered an option for selected cases rather than a standard method. C2 pedicle screws provide sufficient stabilization in most cases. However, in cases of structural defects and congenital malformations, combined with poor bone quality, strong and stable fixation is indicated. The decision to apply 4-point fixation points in C2 needs to be carefully chosen by the surgeon. It depends on many factors and is individual in each case; however, we feel that this is another option for surgeons to augment the stability of the construct. The cases we present in this report had posterior 


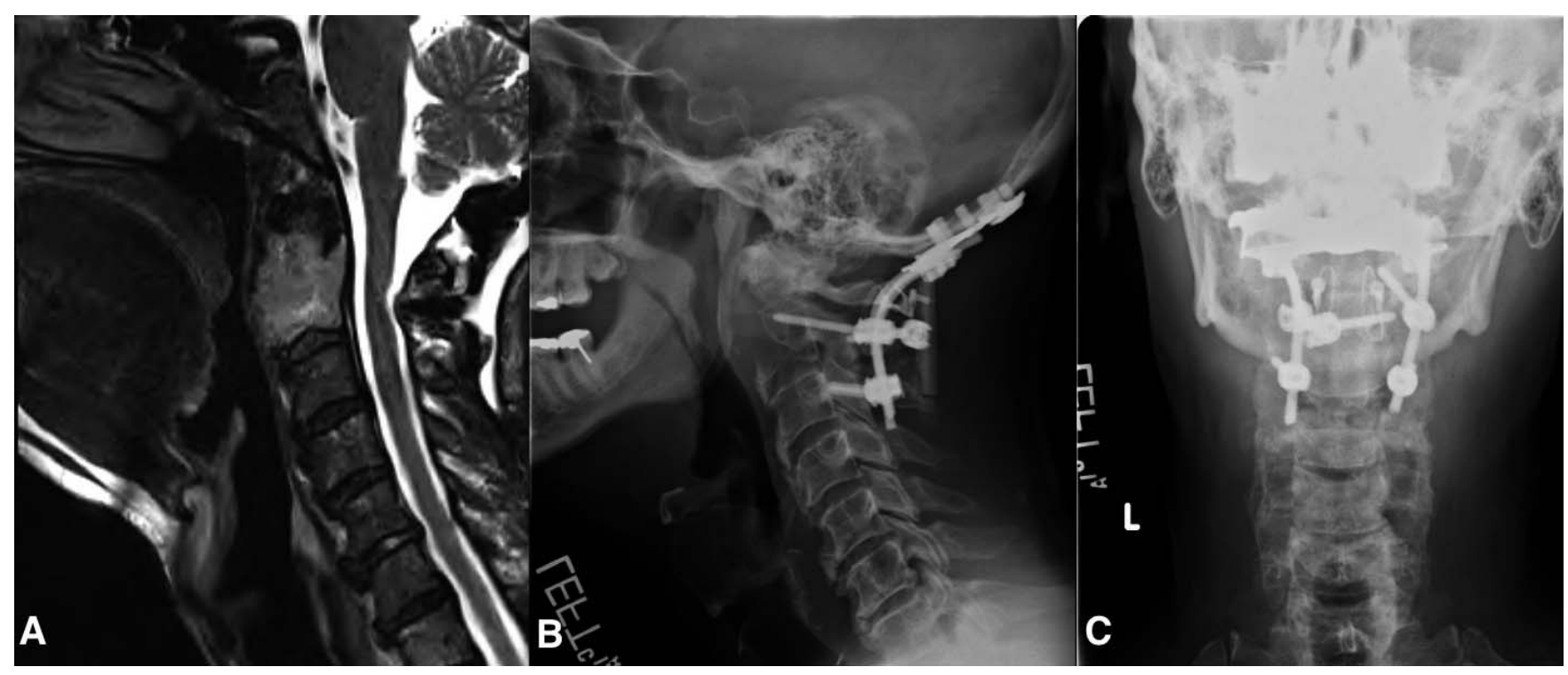

Figure 8. A 60-year-old male who was diagnosed with destructive meningioma of the C2 vertebral body and posterior spinal elements. The patient underwent an instrumented occiput to $\mathrm{C} 3$ posterior spinal fusion. There was destruction of the left $\mathrm{C} 2$ pedicle; therefore, no pedicle screw was placed on that side.

element anomalies that precluded successful subaxial spine instrumentation, warranting, in our opinion, as many points of fixation as feasible in the remaining anatomical structures. Future directions should include studying the biomechanics and clinical results of the 4 -anchor technique.

\section{CONCLUSION}

The axis serves as a versatile anchor point and offers 4 potential points of fixation. Lateral connectors play a crucial role and allow for incorporation of the $\mathrm{C} 2$ screws into the rest of the construct. Local anatomy will dictate the necessity and the ability to place instrumentation, and detailed preoperative planning is of paramount importance. Indications for 4-point fixation are individual, and each case must be carefully evaluated.

\section{REFERENCES}

1. Grob D, Magerl F. Surgical stabilization of C1 and C2 fractures [in German]. Orthopade. 1987;16(1):46-54.

2. Reilly TM, Sasso RC, Hall PV. Atlantoaxial stabilization: clinical comparison of posterior cervical wiring technique with transarticular screw fixation. J Spinal Disord Tech. 2003; 16(3):248-253.

3. Harms J, Melcher RP. Posterior C1-C2 fusion with polyaxial screw and rod fixation. Spine (Phila Pa 1976). 2001;26(22):2467-2471.

4. Parker S, McGirt M, Garcés-Ambrossi G, et al. Translaminar versus pedicle screw fixation of $\mathrm{C} 2$ : comparison of surgical morbidity and accuracy of 313 consecutive screws. Neurosurgery. 2009;64(5, suppl 2):343-348; discussion 348-349.
5. Huang DG, Hao DJ, He BR, et al. Posterior atlantoaxial fixation: a review of all techniques. Spine J. 2015;15(10):22712281.

6. Uehara M, Takahashi J, Hirabayashi H, et al. Computerassisted C1-C2 transarticular screw fixation "Magerl Technique" for atlantoaxial instability. Asian Spine J. 2012;6(3):168177. https://doi.org/10.4184/asj.2012.6.3.168.

7. Kawaguchi Y, Nakano M, Yasuda T, et al. Development of a new technique for pedicle screw and Magerl screw insertion using a 3-dimensional image guide. Spine (Phila Pa 1976). 2012;37(23):1983-1988.

8. Wright N. Posterior C2 fixation using bilateral, crossing C2 laminar screws: case series and technical note. J Spinal Disord Tech. 2004;17(2):158-162.

9. Igarashi T, Kikuchi S, Sato K, Kayama S, Otani K. Anatomic study of the axis for surgical planning of transarticular screw fixation. Clin Orthop Relat Res. 2003;408:162166.

10. Cassinelli E, Lee M, Skalak A, Ahn NU, Wright NM. Anatomic considerations for the placement of C2 laminar screws. Spine (Phila Pa 1976). 2006;31(24):2767-2771.

11. Du JY, Aichmair A, Kueper J, Wright T, Lebl DR. Biomechanical analysis of screw constructs for atlantoaxial fixation in cadavers: a systematic review and meta-analysis. $J$ Neurosurg Spine. 2015;22(2):151-161.

12. Lehman RA Jr, Dmitriev AE, Helgeson MD, Sasso RC, Kuklo TR, Riew KD. Salvage of C2 pedicle and pars screws using the intralaminar technique: a biomechanical analysis. Spine (Phila Pa 1976). 2008;33(9):960-965.

Corresponding Author: Kris Siemionow, MD, Assistant Professor of Orthopaedics and Neurosurgery, Department of Orthopaedics, University of Illinois Medical Center, 835 South Wolcott Ave, Chicago, IL 60612. Phone: (312) 
996-7161; Fax: (312) 996-9025; Email: siemiok@ gmail.com.

Published 15 October 2018

This manuscript is generously published free of charge by ISASS, the International Society for the Advancement of Spine Surgery. Copyright (c) 2018 ISASS. To see more or order reprints or permissions, see http://ijssurgery.com. 